\title{
Translation and Pilot Test of the Implementation Leadership Scale in Chinese Nursing Context
}

Keywords: leadership; evidence-based practice; nursing; translations; linguistics

\section{Running Title: Developing Chinese Implementation Leadership Scale}

Jiale Hu, Wendy Gifford^, Hong Ruan*, Denise Harrison, Qingge Li, Mark G. Ehrhart, Gregory

\author{
A. Aarons
}

Jiale $\mathrm{Hu}(\mathrm{RN}, \mathrm{MScN})$ is a PhD Candidate in school of nursing at University of Ottawa, Ontario, Canada.

Wendy Gifford (RN, PhD) is an associate professor in Faculty of Health Science, University of Ottawa, Ontario, Canada and the co-Director of Center for Research on Health and Nursing, University of Ottawa.

Hong Ruan (RN, MScN) is the Director of Nursing Education and Research, Shanghai Ninth People's Hospital and also the vice president at Shanghai Nursing Association, China.

Denise Harrison (RN, $\mathrm{PhD}$ ) is an associate professor in Faculty of Health Science, University of Ottawa, Ontario, Canada and a Chair in Nursing Care of Children, Youth and Families, Children's Hospital of Eastern Ontario Research Institute.

Qingge $\mathrm{Li}(\mathrm{RN}, \mathrm{BScN})$ is a student in master nursing program, Shanghai Jiaotong University, China.

Mark G. Ehrhart $(\mathrm{PhD})$ is a Professor in the Industrial/Organizational Psychology Program at the University of Central Florida.

This is the author manuscript accepted for publication and has undergone full peer review but has not been through the copyediting, typesetting, pagination and proofreading process, which may lead to differences between this version and the Version of Record. Please cite this article as doi: $\underline{10.1111 / J O N M .12768}$

This article is protected by copyright. All rights reserved 
Gregory A. Aarons (PhD) is a Professor and Director of the Child and Adolescent Services Research Center in the Department of Psychiatry at the University of California, San Diego, USA.

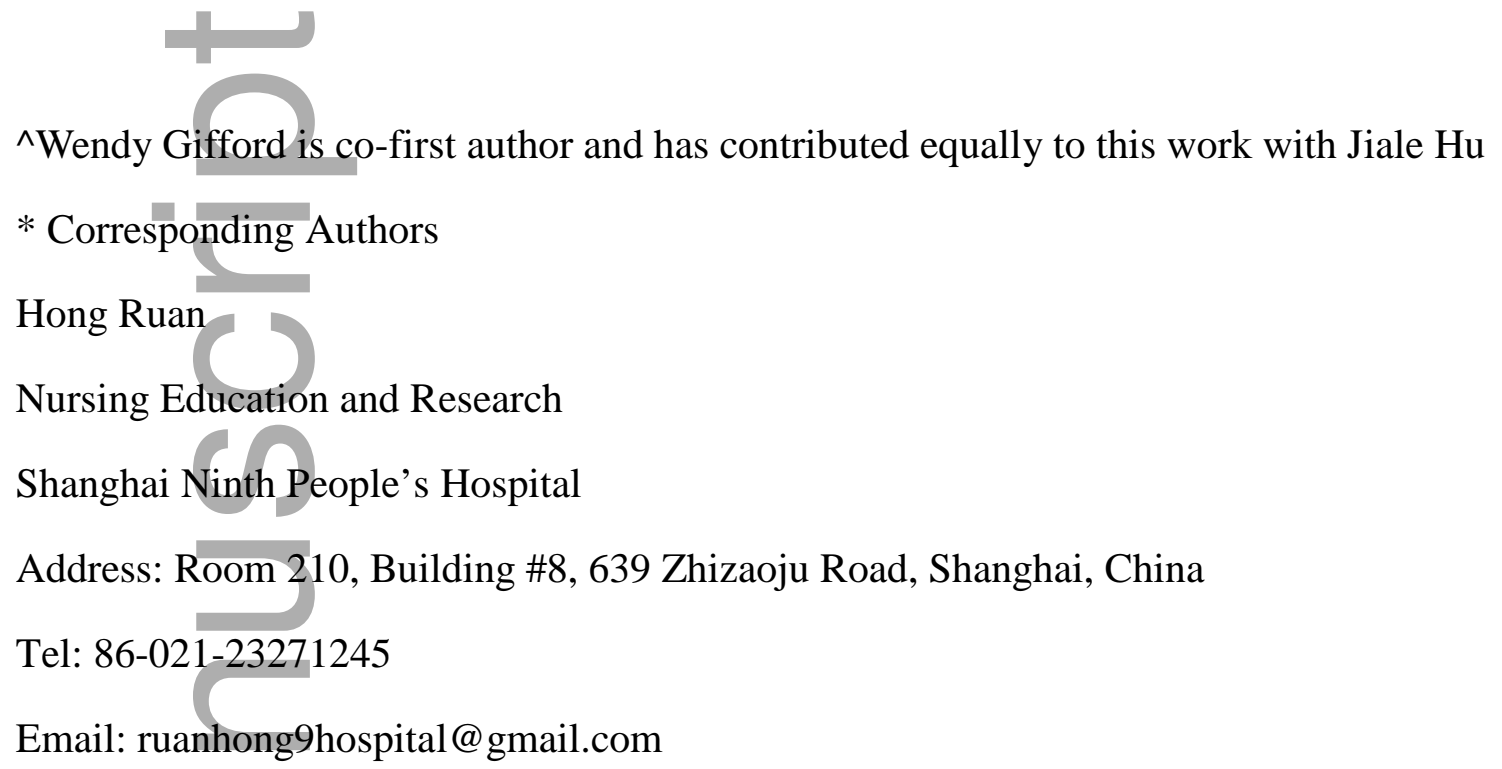

Conflict of interest: The authors disclose no conflict of interest.

\section{Funding}

This study was funded by University of Ottawa International Research Acceleration Program (2016-2018). The first author (Hu) was supported by Ontario Trillium Scholarship (2015-2019) in a PhD program at the University of Ottawa. Drs. Aarons and Ehrhart were supported by grants from the United States National Institute of Mental Health R21MH098124 (PI: Ehrhart), R21MH082731 and R01MH072961 (PI: Aarons) and National Institute on Drug Abuse R01DA038466 (PI: Aarons).

\section{Acknowledgements}

Thanks are due to all the translation committee and participants in the interview for their time, support and suggestions throughout this study. Also, the authors appreciate Brianna 
Hammond, Yiyan Zhou, Zeina Al Awar, Leilei Yu, and Sarah Running for their efforts and research assistance.

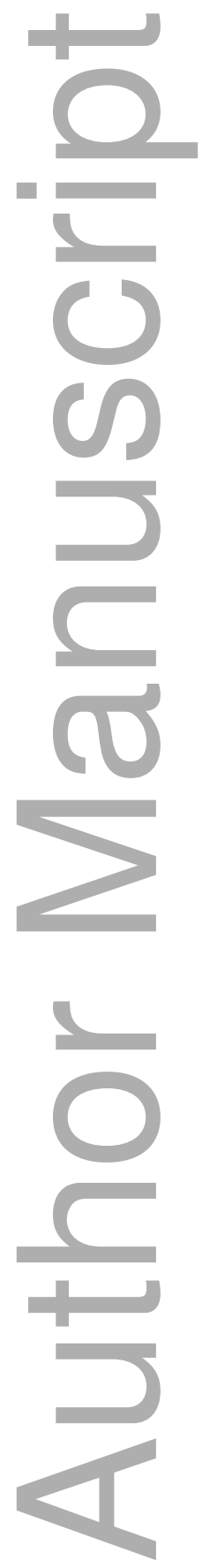

This article is protected by copyright. All rights reserved 
2 DR JIALE HU (Orcid ID : 0000-0003-1993-8704)

3

4 instrument.

Conclusion: This study provided a deep understanding of using the ILS in the local context and laid the foundation for future psychometric statistical testing. 
1 Implications for nursing management: ILS could support organizational leadership

2 development programs and strategies to facilitate and support EBP implementation and

3 sustainment.

4 Keywords:

5 leadership; evidence-based practice; nursing; translations; linguistics

61 Introduction

7 Sackett (1996) defined evidence-based practice (EBP) as "the use of current best

8 evidence in making decisions about the care of individual patients that integrates the best

9 external evidence with individual clinical expertise and patients' choice (Sackett, Rosenberg,

10 Gray, Haynes, \& Richardson, 1996).” It is widely accepted that EBP is a significant

11 advancement in health care services that promotes optimal clinical practice and positive

12 patient outcomes (Grol \& Grimshaw, 2003). As the largest professional group in health care

13 delivery, nurses play a central role in advancing the implementation of EBP (World Health

14 Organization, 2016). In 2012, the International Council of Nurses proposed the theme

15 "Closing the Gap: From Evidence to Action" as a means of encouraging nurses to use evidence-based approaches to nursing practice (International Council of Nurses, 2012).

17 However, EBP remains inconsistently applied with formidable implementation challenges

18 (Melnyk, Fineout-Overholt, Gallagher-Ford, \& Kaplan, 2012).

EBP was introduced to the context of Chinese nursing in 2001, and is now considered a

20 critical step in scaling up the quality and effectiveness of nursing services in China (Cheng,

21 Feng, \& Hu, 2017; The Lancet, 2012). A recent scoping review illustrated that the number of

22 studies conducted in China on the implementation of EBP in nursing has been gradually

23 increasing each year, from zero in 2001 to 28 in 2015 (Cheng, Feng, et al., 2017). However,

24 this review also revealed that implementing EBP in the Chinese nursing context has its own

25 unique challenges and system wide barriers. For example, barriers include widely held

26 cultural values of respect for position, age, and working experience hierarchies and the

27 pursuit of social harmony, most of which cannot be addressed in a short period of time

28 (Cheng, Feng, et al., 2017).

This article is protected by copyright. All rights reserved 
Leadership is considered a critical factor for the implementation of EBP in different settings and among different professional groups (Gifford et al., 2018; Hu \& Gifford, 2018).

3 However, few published studies have focused on leadership for implementing EBP in China.

4 Specifically, what leaders do to facilitate and support EBP has not been considered in

5 Chinese nursing research (Cheng, Broome, Feng, \& Hu, 2017a, 2017b) which has created a

6 knowledge gap about implementation leadership in this context. To advance the science, a

$7 \quad$ valid and reliable measurement tool is needed to understand how leadership influences

8 implementation of EBP in Chinese nursing settings.

Without a validated, reliable, and acceptable measurement tool of implementation leadership, it is difficult to evaluate what nursing leaders do to implement EBP, or the impact of leadership interventions for improving nurses' attitudes, acceptance and implementation of EBP. Previous studies have used questionnaires measuring leadership in general to evaluate leadership for the implementation of EBP, such as the Multifactor Leadership Questionnaire including transformational and transactional leadership (Aarons \& Aarons, 2006; Aarons, Ehrhart, Moullin, Torres, \& Green, 2017; Brimhall et al., 2015; Marchionni \& Ritchie, 2008; Masood \& Afsar, 2017; Paparone, 2015; Powell et al., 2017). Leadership in general refers to a process of influencing others to accomplish shared objectives (Yukl, 2006), however instruments measuring leadership in general do not capture the particular leadership strategies and behaviors that are critical to implementing EBP (Aarons, Ehrhart, \& Farahnak, 2014).

One meta-analysis of 58 studies demonstrated that strategic leadership that focusses on activities for a specific organizational change initiative has a relative advantage when compared to leadership in general (Hong, Liao, Hu, \& Jiang, 2013). In EBP context, this means that the evaluation of leadership that focuses specifically on implementation could predict implementation of EBP more accurately than those that focus on leadership in general (Aarons et al., 2014). It is therefore warranted that a valid and reliable instrument that measures implementation leadership in the Chinese nursing context is needed to understand 27 and evaluate EBP efforts. 
Aarons et al. (2014) developed the Implementation Leadership Scale (ILS), a valid and

2 reliable tool that focuses specifically on leadership for implementing EBP. The ILS measures

3 the degree to which a leader is proactive, knowledgeable, supportive, and perseverant in their

4 efforts to implement EBP (Aarons et al., 2014). The ILS includes 12 items scored on a scale

5 of 0 (not at all) to 4 (a very great extent) (Aarons et al., 2014). There are two versions of the

6 ILS: one allows staff to assess their supervisor/leader, and another for supervisors/leaders to

7 assess themselves (Aarons et al., 2014). Both staff and supervisor versions have the same 12

8 statements, but differ in the referent of the items (the supervisor name being used in the staff

9 version, which is replaced by " $\mathrm{I}$ " in the supervisor version).

10 The ILS has been validated in mental health clinics with clinicians (Cronbach's alpha

11 0.98), alcohol and drug use treatment agencies with counselors (Cronbach's alpha 0.97), and

12 child welfare services with social workers and other allied health professionals (Cronbach's

13 alpha 0.97)(Aarons et al., 2014; Aarons, Ehrhart, Torres, Finn, \& Roesch, 2016; Finn, Torres,

14 Ehrhart, Roesch, \& Aarons, 2016). It has shown to be an efficient and pragmatic scale for

15 capturing leadership behaviors with which to implement EBP (Aarons et al., 2016). However,

16 these studies were all conducted in the English language in United States of America, and it

17 is unclear how ILS items and constructs would be interpreted and understood in Chinese

18 settings. Thus, the purpose of this study was to translate the ILS into Chinese and conduct

19 linguistic validation of the translated ILS in a Chinese nursing context. We undertook this study as part of a larger project to evaluate a leadership intervention for nurse managers to implement and support evidence-based pain management practices in infants and children in a large acute care hospital in China.

\section{Methods}

This study followed a systematic process from the guideline developed by Sousa and Rojjanasrirat (2011), which was based on a comprehensive review of methodological approaches to translation, adaptation, and validation of instruments for cross-cultural research

27 (Sousa \& Rojjanasrirat, 2011).

\subsection{Step 1: Forward Translation}


The supervisor version and staff version of the original English (source language) ILS

2 were combined and then translated independently into written Chinese (target language) by

3 two bilingual translators who had experience living in China and Western countries (termed

4 bicultural). One translator was a registered nurse with over five years experience working in

5 both China and Canada, and was knowledgeable about health care terminology and

6 leadership. The other was a certified translator from China who had lived in an English

7 language country (Australia) for more than 10 years.

$8 \quad 2.2$ Step 2: Comparison of the Two Forward Translation Versions examined discrepancies between words, sentences, and meanings. The committee was composed of five nursing scholars in China with different experiences and clinical backgrounds (see Table 1). The committee discussed discrepancies and evaluated whether the translation was: 1) conceptually understood in the Chinese nursing context (conceptual equivalence); 2) correctly reflected the intended English meaning (semantic equivalence); 3) accepted by targeted respondents (item equivalence); and 4) had wording, format, instruction and scaling that could be used in Chinese nursing context (operational equivalence). Questions that could not be resolved by the forward-translation committee were discussed with the tool developers in the United States (GAA, ME) until consensus was reached.

\subsection{Step 3: Blind Backward Translation}

The preliminary Chinese ILS (Post-Forward Translation) was then translated back into English by two different independent translators with qualifications similar to those of the forward translators. The backward translators had no previous exposure to the original English ILS.

\subsection{Step 4: Comparison of the Two Backward Translation Versions}

Similar to the forward translation comparisons, a backward translation committee was established to compare the backward translation versions and resolve discrepancies. This committee included one doctorate candidate who was bilingual in Chinese and English (JH), two nursing professors (WG, DH) and the ILS tool developers (GAA, ME). The committee 
1 also compared the backward translated versions with the original English ILS, evaluating

2 whether the back translation correctly reflected the intended meanings of the original. If the

3 intended meaning of the back-translated ILS had been altered through the translation process,

4 the related translated words underwent steps one to four again as outlined above. This cycle was repeated until all backward translation of the ILS were acceptable to the committee.

\subsection{Step 5: Linguistic Validation}

Linguistic validation evaluates how participants understand and respond to the instruments and assesses the clarity, intelligibility, appropriateness, and cultural relevance of the target language version to the target population (Mear I. \& Giroudet C., 2012). It is strongly recommended as an important and necessary step before psychometric and statistical testing in local context (Egger-Rainer, 2018; Sousa \& Rojjanasrirat, 2011). In this study, the cognitive interviewing methods, including think-aloud, verbal probing, and vignettes, were used to complete linguistic validation (see Table 2) (Nichols E. \& Childs J.H., 2009; Willis, 2005). leaders having more than three years working experience in their current positions in China. Interviews were conducted in Chinese. Their audio recordings were transcribed by one research assistant (QL) and checked by another (YZ). Investigator triangulation was used to offer completeness in the data analysis. It involved an independent analysis of interviews by different investigators followed by research team discussions of findings (Tobin \& Begley, 2004). Interview transcripts in Chinese were entered into NVivo (version 11 for Windows) qualitative software and analyzed for cognitive requirements and linguistic issues (QSR International, 2019, February 17th). NVivo is a computer software package to facilitate researchers to organize, store, categorize and display data during qualitative data analysis (QSR International, 2019, February 17th).

The analysis was conducted by a study investigator $(\mathrm{JH})$ and two research assistants $(\mathrm{QL}$, YZ), all of whom were bilingual and bicultural. Cognitive requirements included: 1) comprehension (encoding processes), 2) recall (retrieval processes), 3) inference (judgment 
1 processes), 4) mapping (response processes), and 5) editing (processes used to edit answers).

2 All the issues and relevant quotes in Chinese were translated to English (YZ),

3 double-checked (JH, QL), and discussed by the research team and ILS developers.

After the first round of cognitive interview, the research team and ILS developers discussed the required revisions, and the revised ILS went through the forward and backward translation process again and was tested in a further cognitive interview round with different participants (Willis, 2005). This cycle was repeated until no further revisions were needed for linguistic validation.

\subsection{Ethical Approval}

The study was approved by the university and hospital Research Ethics Boards (H02-17-15). Permission to translate the ILS into Chinese was obtained from the developers of the original scale (GAA, ME).

\section{$13 \quad 3$ Results}

\subsection{Translations and Committee Meetings} translation process, 24 translation issues were identified (see Table 3). Both forward and backward translations (with committee meetings) took two rounds to address all the translation issues and develop the preliminary translated ILS.

The most frequently identified translation issue was semantic equivalence (16 issues). Forward translation found seven issues with five English terms or phrases that were difficult to match in Chinese, including: "proactive" (conceptual term for Domain 1), "know what I am talking about" (scale item 6), "persevere" (scale item 10), "ups and downs" (scale item 10), and "carry on" (scale item 11). The forward translations of three English terms were

24 found at risk for being misunderstood in a Chinese nursing context (six issues): "supervisor" 25 (Title), "staff" (Title), and "department" (scale item 3). The backward translation committee identified four semantic equivalence issues that involved altering the meaning of the original ILS (scale items 3, 9, 10, 12). 
One issue arose for the operational equivalency translation of the scale. The backward

2 translation committee found the "extent" to which respondents would agree with each item in

3 the scale to be confusing to understand. The middle rating of number "two" on the 0-4 Likert

4 scale had been translated into "neutral" but was deemed not incrementally equivalent to the

5 difference between number "one" (slight extent) and number "three" (great extent), altering

6 the operational equivalency of the original ILS. Therefore, the "extent" was revised to be

7 continuous to allow respondents to gradually increase their agreement with each statement.

8 All five conceptual equivalency issues occurred with the terms "implementation

9 leadership" and "evidence-based practice.” Leadership for implementing evidence-based practice specifically was translated to represent the concept of "implementation leadership."

11 In order to help participants understand what "evidence-based practice" means, it was

12 decided to test four examples in the cognitive interviews and add the most acceptable one to

13 the scale.

14 Two item equivalence issues were identified in the forward translation committee meeting for items that were not originally considered difficult to translate. The first was the "Name of supervisor" for each item in the staff version of the ILS; and the second was "I am able to answer staff's questions about evidence-based practice" (scale item 5). These issues underwent further tests in the cognitive interviews to evaluate whether the translated terms were acceptable to Chinese nursing staff and leaders.

\subsection{Cognitive Interview and Adaptation}

Two rounds of cognitive interviews were conducted. Fourteen nurses were invited to participate in round one and twelve in round two of the cognitive interviews. Ten nurses participated in each round, corresponding to a $71 \%$ response rate in round one and $83 \%$ response rate in round two (see Table 4). Thirty-three linguistic issues were uncovered: 25 in the first round and eight in the second (see Table 5). The final Chinese ILS (Supervisor Version and Staff Version) in this study had seven significant adaptations to the original instrument, including three changes in the instruction, three changes in 12 items of the ILS, and one added investigator guide for modifying "department” as required (see Figure 1). 
The issues most commonly identified by participants were linguistic issues regarding

2 comprehension (25 issues). Three comprehension linguistic issues were caused by a lack of

3 known Chinese words that appropriately reflect the intended meaning of two of ILS's English

4 terms: "standards" (scale item 3) and "appreciate" (scale item 7). The research team and the

5 ILS tool developers discussed the meaning of these two terms using the Oxford English

6 Dictionary and then identified an equivalent Chinese wording based on the dictionary

7 definitions (Oxford English dictionary, 2018). The equivalent Chinese meaning of "standards"

8 was deemed "expectation or requirements for a level of quality or attainment," and that of

9 "appreciate" was "recognize a person in a good way."

10 Six participants argued that the term "removed" in scale item 2 ("I have removed

11 obstacles to the implementation of evidence-based practice") was a final and completed

12 action, for which it was difficult to provide a gradual or continuous extent of agreement. Thus,

13 the term "removed" was changed to "worked to minimize" in the Chinese version (see

14 Adaptation One in Figure 1). Eight participants had trouble responding to scale item 12 ("I

15 react to critical issues regarding the implementation of evidence-based practice by openly and

16 effectively addressing the problem(s)") because it seemed to reference multiple behaviors and

17 made it unclear to which of them they had to respond. They were unsure if they had to

18 evaluate the extent to which the reaction was "open," "effective" or "addressed the

19 problem(s). Thus, this item was simplified to focus on the extent to which participants

20 "address critical issue(s) regarding the implementation of evidence-based practice." (see

21 Adaptation Two in Figure 1).

22 Understanding "evidence-based practice" was another concern for respondents. Four

23 respondents were unable to define the concept correctly and six could not link it to what they

24 did in the clinical setting. Thus, participants were provided with Sackett's (1996) definition

25 of EBP to assist their understanding (Sackett et al., 1996). Four pre-determined examples of

26 EBP were discussed and participants voted on their preferred example. Using normal saline

27 instillation prior to endotracheal suctioning only if clinically indicated (i.e. not routinely) was 
1 considered the most robust example of EBP in the Chinese nursing context, and was therefore

2 included in the scale's instructions (see Adaptation Three in Figure 1).

3 Linguistic issues regarding recall or inference arose when respondents were asked to

4 evaluate leadership behaviors as being "knowledgeable about evidence-based practice."

5 Moreover, they had difficulties mapping their evaluation of these behaviors on a five-point

6 Likert scale. Therefore, the instruction "All answers are based on your perception of

7 leadership behavior. If you are not sure, please give the best answer you think" was added to

8 the Chinese ILS, to help respondents understand the intent behind each question (see

9 Adaptation Four in Figure 1).

10 In the original version, item 3 ("I have established clear department standards for the

11 implementation of evidence-based practice") substituted the term "department" with "unit," if

12 it was predetermined that "unit" would be understood more readily in the implementation

13 context. A guide, with an example, was included in the Chinese ILS, to help investigators

14 pre-determine and modify appropriate terms before administering the questionnaire (see

15 Adaptation Five in Figure 1).

16 There was one linguistic issue with the staff version of the ILS. The study investigators

17 had predetermined and filled in the "Name of Supervisor" prior to administration, but

18 participants were concerned that naming the supervisor on the questionnaire would make

19 respondents in China uncomfortable, which might affect their ability to complete the survey truthfully. Therefore, the "Name of Supervisor" item was replaced by the term "Your

21 Supervisor," and a note was added in the instructions that read "Supervisor means the direct nursing leader supervising you most in clinical practice," to ensure respondents were aware of whom they were rating (see Adaptation Six and Seven in Figure 1).

All eight linguistic issues in the second round were considered to be minor. For example, one participant believed scale item 11 ("I carry on through the challenges of implementing evidence-based practice") could be misunderstood because "If there are too many challenges,

27 I think it is not necessary to carry on, as many challenges might mean the evidence is not appropriate for my clinical setting." The team discussed incorporating further explanations to 
1 the related question, such as adding "when the evidence is appropriate" to the end of the item.

2 However, no alterations were made out of concern for the face validity of the original scale.

\section{Discussion}

The implementation of EBP in the Chinese nursing context is on the rise (Cheng, Feng, et al., 2017), and leadership is likely to play a significant role in the successes or failures of such implementation efforts (Gifford et al., 2018; Hu \& Gifford, 2018). Thus, validated measures of implementation leadership are needed to determine the degree to which leadership affects EBP adoption, implementation, and sustainment. This paper presented the creation of a Chinese version of the ILS, which was translated and adapted from the original instrument through a systematic and rigorous process. The Chinese ILS has the potential to play an important role in research on the development of implementation leadership in Chinese nursing and provides a common language for investigators conducting research in China to investigate and understand leadership within implementation science.

High quality translation and linguistic validation are foundation for psychometric and statistical testing (Streiner, 2008). In this study, we followed the rigorous guideline for translation and linguistic validation (Sousa \& Rojjanasrirat, 2011), detailing the issues of translation equivalency that arose and the strategies used to address them. In addition to increasing researchers' confidence in the quality of the Chinese ILS, the comprehensive reporting featured in this study can facilitate researchers to translate the ILS into other languages, or other measurement tools into Chinese (Acquadro, Conway, Hareendran, \& Aaronson, 2008; Sousa \& Rojjanasrirat, 2011). Findings will support the interpretation of further psychometric testing and contribute to understanding the scores of the Chinese ILS when used in future studies (Sousa \& Rojjanasrirat, 2011; Streiner, 2008).

Holding meetings with the translation committee regarding the forward and backward translation processes helped identify any discrepancies and improved translation quality (Sousa \& Rojjanasrirat, 2011). While most ILS items were deemed not difficult to translate in forward translation, the committee discovered multiple discrepancies between the first and second forward translations. After meticulous detailing each stage of the translation process, 
1 the translation committee identified a number of incongruences between the original English

2 and Chinese versions. We used multiple approaches to resolve these issues, which included

3 discussing the differences of multiple translation options, using the Oxford English

4 Dictionary to clarify English terms, and repeating the forward and backward translation

5 process until the results were acceptable to the committee.

The primary challenge in translating and linguistically validating the ILS was finding the

7 appropriate Chinese words and expressions for some of the items specific to implementation

8 leadership. For example, the term "implementation leadership" was not known or well

9 understood to the translators and participants and therefore they lacked the appropriate

10 Chinese words. The research team and ILS developers discussed this issue and decided to use

11 "sense-to-sense translation" rather than "word-to-word translation" to come up with a

12 conceptual representation of what "implementation leadership" means in Chinese (Gentzler,

13 2001). In cases where one English term had different meanings, such as with the words

14 "standards" and "appreciate", the Oxford English Dictionary provided an effective way to

15 identify different meanings and clarify the intentions of the original ILS with the developers

16 to confirm the translated term.

17 The discussions between the research team and the instrument developers over the course of the study were vital to the quality of the final Chinese ILS. Not only were the discussions useful in decision making in different translation and validation stages, but they helped determine when the forward and backward translation stages were complete and whether revisions or adaptations to the tool were necessary. The research team and instrument developers made a number of targeted and strategic changes based on judgments regarding the potential benefits and/or disadvantages of each revision, prioritizing the most unclear and important changes.

Although the concept of "evidence-based practice" was introduced in China in 2001, it remains unfamiliar to Chinese nursing leaders and staff (Cheng, Feng, et al., 2017). Most of the leaders and staff interviewed in our study learned about EBP in university courses or continuing education programs, but found it difficult to see its relevance to their clinical work. 
1 To clarify the meaning of EBP, Sackett's definition (Sackett et al., 1996) along with an

2 example of EBP that was identified by participants (not using normal saline instillations prior

3 to endotracheal tube suctioning), were added to the Chinese ILS scale.

4 The modification to replace inserting the supervisor's name in the original ILS to the 5 more referent of "your supervisor" in the Chinese version was considered an important

6 linguistic change because respect for hierarchy and pursuit of harmony with others is strongly

7 emphasized and embedded within Chinese culture (Cheng, Broome, et al., 2017a; Cheng,

8 Feng, et al., 2017). This meant that identifying a supervisor's name on the Chinese ILS had

9 the added risk of respondents answering favorably, increasing the risk of social desirability

10 bias (Streiner, 2008). Respondents also felt that removing obstacles (item 2) was too finite

11 but "minimizing obstacles" reflected the work reality more accurately and allowed

12 respondents to gradually increase their extent of agreement. Regarding item 12, the ILS

13 developers clarified that addressing critical issues was the core behavior the item was intended to address, and we therefore removed the extra English terms (such as "reacts to," "openly and effectively") that were redundant to the Chinese testers and risked misinterpreting the item.

\subsection{Implication for nursing management}

Given that the Chinese ILS is a brief measure of implementation leadership, it has little respondent burden and is therefore practical to use in nursing research settings where efficiency is paramount. The Chinese ILS can inform researchers' and nursing managers' understanding of how nursing leaders implement EBP in China. In addition, the Chinese ILS can be used as a tool to identify nursing leader, or to understand areas in need of development in existing leaders for implementing EBP. Nursing managers could use data that has been generated from the ILS to support leadership development strategies in their organizations to facilitate and support EBP implementation and sustainment.

\subsection{Limitations}

Despite its robustness, our study had limitations. First, the cognitive interviews were conducted in Shanghai, which has more educational resources on leadership and EBP than 
1 other smaller cities in China. Therefore, participants in this study might have been more

2 likely to be exposed to the concept of leadership and EBP that other samples. Second, the

3 cognitive interviews were conducted and analyzed in Chinese, and the results with

4 subsequent quotes were then translated to English. This meant that not every investigator had

5 the chance to read the original transcripts, which may add bias. However, investigator

6 triangulation was utilized to ensure the completeness of data analyses.

\section{Conclusion} nursing context. Having the original instrument developers involved in this process enhanced the robustness of the translation and linguistic validation. This study provided a deep understanding of using the ILS in the local Chinese context and emphasized the importance of understanding the different contexts where an instrument is developed and to be used. The

14 Chinese ILS now requires further assessments in the local context using psychometric testing. Statistical testing is currently in progress and the psychometric characteristics of the Chinese ILS will be provided in a future report.

Figure Legends

Figure 1. The adaptations in the Chinese Implementation Leadership Scale

References

Aarons, G. A., \& Aarons, G. A. (2006). Transformational and transactional leadership: association with attitudes toward evidence-based practice. Psychiatric Services, 57(8), $1162-1169$.

Aarons, G. A., Ehrhart, M. G., \& Farahnak, L. R. (2014). The implementation leadership scale (ILS): development of a brief measure of unit level implementation leadership. Implementation Science, 9(45), 1-10. doi: https://doi.org/10.1186/1748-5908-9-45 
1 Aarons, G. A., Ehrhart, M. G., Moullin, J. C., Torres, E. M., \& Green, A. E. (2017). Testing the leadership and organizational change for implementation (LOCI) intervention in substance abuse treatment: a cluster randomized trial study protocol. Implementation Science, 12(1), 29.

Aarons, G. A., Ehrhart, M. G., Torres, E. M., Finn, N. K., \& Roesch, S. C. (2016). Validation of the Implementation Leadership Scale (ILS) in Substance use Disorder Treatment Organizations. J Subst Abuse Treat, 68, 31-35. doi: https://doi.org/10.1016/j.jsat.2016.05.004

Acquadro, C., Conway, K., Hareendran, A., \& Aaronson, N. (2008). Literature review of methods to translate health-related quality of life questionnaires for use in multinational clinical trials. Value Health, 11(3), 509-521. doi: https://doi.org/10.1111/j.1524-4733.2007.00292.x

Brimhall, K. C., Fenwick, K., Farahnak, L. R., Hurlburt, M. S., Roesch, S. C., \& Aarons, G. A. (2015). Leadership, Organizational Climate, and Perceived Burden of Evidence-Based Practice in Mental Health Services. Administration \& Policy in Mental Health, 43(5), 629-639.

Cheng, L., Broome, M. E., Feng, S., \& Hu, Y. (2017a). Factors influencing the implementation of evidence in Chinese nursing practice. J Clin Nurs, 26, 5103-5112. doi: https://doi.org/10.1111/jocn.14053

Cheng, L., Broome, M. E., Feng, S., \& Hu, Y. (2017b). Taking Root: a grounded theory on evidence-based nursing implementation in China. Int Nurs Rev, 65(2), 270-278. doi: https://doi.org/10.1111/inr.12396

Cheng, L., Feng, S., \& Hu, Y. (2017). Evidence-based nursing implementation in Mainland China: A scoping review. Nurs Outlook, 65(1), 27-35. doi: https://doi.org/10.1016/j.outlook.2016.07.016

Egger-Rainer, A. (2018). Enhancing validity through cognitive interviewing. A methodological example using the Epilepsy Monitoring Unit Comfort Questionnaire. J Adv Nurs. doi: 10.1111/jan.13867 
1 Finn, N. K., Torres, E. M., Ehrhart, M. G., Roesch, S. C., \& Aarons, G. A. (2016). Cross-Validation of the Implementation Leadership Scale (ILS) in Child Welfare Service Organizations. Child Maltreat, 21(3), 250-255. doi: $10.1177 / 1077559516638768$

Gentzler, E. (2001). Contemporary translation theories (2nd ed., pp. 112-120). Clevedon, England; Buffalo, N.Y.: Multilingual Matters.

Gifford, W.A., Squires, J. E., Angus, D. E., Ashley, L. A., Brosseau, L., Craik, J. M., . . Graham, I. D. (2018). Managerial leadership for research use in nursing and allied health care professions: a systematic review. Implement Sci, 13(1), 127. doi: 10.1186/s13012-018-0817-7

Grol, R., \& Grimshaw, J. (2003). From best evidence to best practice: effective implementation of change in patients' care. Lancet, 362(9391), 1225-1230. doi: https://doi.org/10.1016/s0140-6736(03)14546-1

Hong, Y., Liao, H., Hu, J., \& Jiang, K. (2013). Missing link in the service profit chain: a meta-analytic review of the antecedents, consequences, and moderators of service climate. J Appl Psychol, 98(2), 237-267. doi: https://doi.org/10.1037/a0031666

Hu, J., \& Gifford, W. (2018). Leadership behaviours play a significant role in implementing evidence-based practice. J Clin Nurs, 27(7-8), e1684-e1685. doi: https://doi.org/doi.org/10.1111/jocn.14280

International Council of Nurses. (2012). Closing the gap from evidence to action. Retrieved June 4, 2017, from http://www.icn.ch/publications/2012-closing-the-gap-from-evidenceto-action/.

Marchionni, C., \& Ritchie, J. (2008). Organizational factors that support the implementation of a nursing best practice guideline. Journal of Nursing Management, 16(3), 266-274.

Masood, M., \& Afsar, B. (2017). Transformational leadership and innovative work behavior among nursing staff. Nurs Inq, 24(4). doi: 10.1111/nin.12188 
1 Mear I., \& Giroudet C. (2012). Linguistic Validation Procedures. In Acquadro C., Conway K.,

Giroudet C. \& Mear I. (Eds.), Linguistic Validation Manual for Health Outcome Assessments (2nd ed., pp. 48-67): MAPI Institute.

Melnyk, B. M., Fineout-Overholt, E., Gallagher-Ford, L., \& Kaplan, L. (2012). The state of evidence-based practice in US nurses: critical implications for nurse leaders and educators. J Nurs Adm, 42(9), 410-417. doi: https://doi.org/10.1097/NNA.0b013e3182664e0a

Nichols E., \& Childs J.H. (2009). Respondent debriefings conducted by experts: A technique for questionnaire evaluation. Field Method, 21(2), 115-132. doi: https://doi.org/10.1177/1525822X08330265

Oxford English dictionary. (2018). Oxford English dictionary (pp. 618). Oxford, England]: Oxford, England : Oxford University Press.

Paparone, P. (2015). Supporting influenza vaccination intent among nurses: effects of leadership and attitudes toward adoption of evidence-based practice. Journal of Nursing Administration, 45(3), 133-138.

Powell, B. J., Mandell, D. S., Hadley, T. R., Rubin, R. M., Evans, A. C., Hurford, M. O., \& Beidas, R. S. (2017). Are general and strategic measures of organizational context and leadership associated with knowledge and attitudes toward evidence-based practices in public behavioral health settings? A cross-sectional observational study. Implementation Science, 12(1), 64.

QSR International. (2019, February 17th). What is NVivo. from https://www.qsrinternational.com/nvivo/what-is-nvivo

Sackett, D. L., Rosenberg, W. M., Gray, J. A., Haynes, R. B., \& Richardson, W. S. (1996). Evidence based medicine: what it is and what it isn't. Bmj, 312(7023), 71-72. doi: https://doi.org/10.1136/bmj.312.7023.71

Sousa, V. D., \& Rojjanasrirat, W. (2011). Translation, adaptation and validation of instruments or scales for use in cross-cultural health care research: a clear and

This article is protected by copyright. All rights reserved 
user-friendly guideline. J Eval Clin Pract, 17(2), 268-274. doi: https://doi.org/10.1111/j.1365-2753.2010.01434.x

Streiner, D. L. (2008). Health measurement scales: a practical guide to their development and use (pp. 248-270). Oxford: Oxford University Press.

The Lancet. (2012). Science for action-based nursing. The Lancet, 379(9828), 1763. doi: https://doi.org/10.1016/s0140-6736(12)60741-7

Tobin, G. A., \& Begley, C. M. (2004). Methodological rigour within a qualitative framework. J Adv Nurs, 48(4), 388-396. doi: https://doi.org/10.1111/j.1365-2648.2004.03207.x

Willis, G. B. (2005). Cognitive interviewing a tool for improving questionnaire design (pp. 42-65). Thousand Oaks, Calif.: SAGE.

World Health Organization. (2016). The global strategic directions for strengthening nursing and midwifery (pp. 14-22). Geneva, Switzerland: World Health Organization.

Yukl, G. A. (2006). Leadership in organizations (6th ed.). Upper Saddle River, NJ: Pearson Prentice Hall.

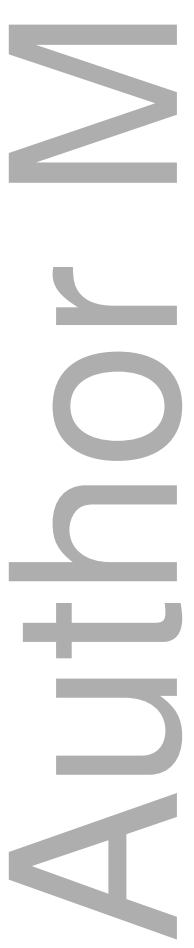


Table 1. Forward Translation Committee

\begin{tabular}{llllc}
\hline & Experience and Clinical Background & Department & Education & Working Years \\
\hline $\mathbf{1}$ & Chief Director & Department of Nursing & Master Degree & 33 \\
$\mathbf{2}$ & Clinical Manager & Division of Internal Medicine & Master Degree & 30 \\
$\mathbf{3}$ & Bedside Nurse & Department of Orthopedics & Bachelor Degree & 14 \\
$\mathbf{4}$ & Nurse Educator & Department of Emergency & Doctoral Degree & 13 \\
$\mathbf{5}$ & Head Nurse and Nurse Researcher & Department of Ophthalmology & Master Degree & 6 \\
\end{tabular}

Note:

* A clinical manager supervises head nurses across numerous clinical departments in one division

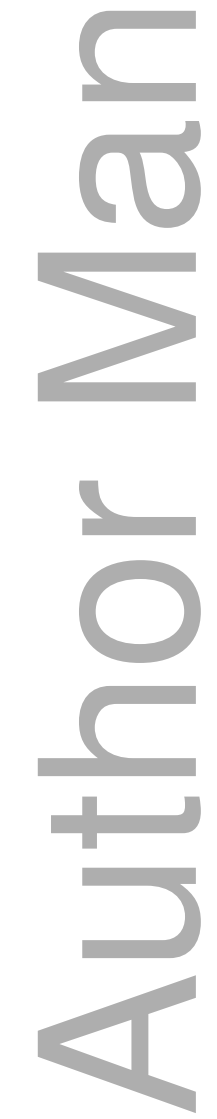

This article is protected by copyright. All rights reserved 
Table 2. Cognitive Interviewing Methods and Example Questions

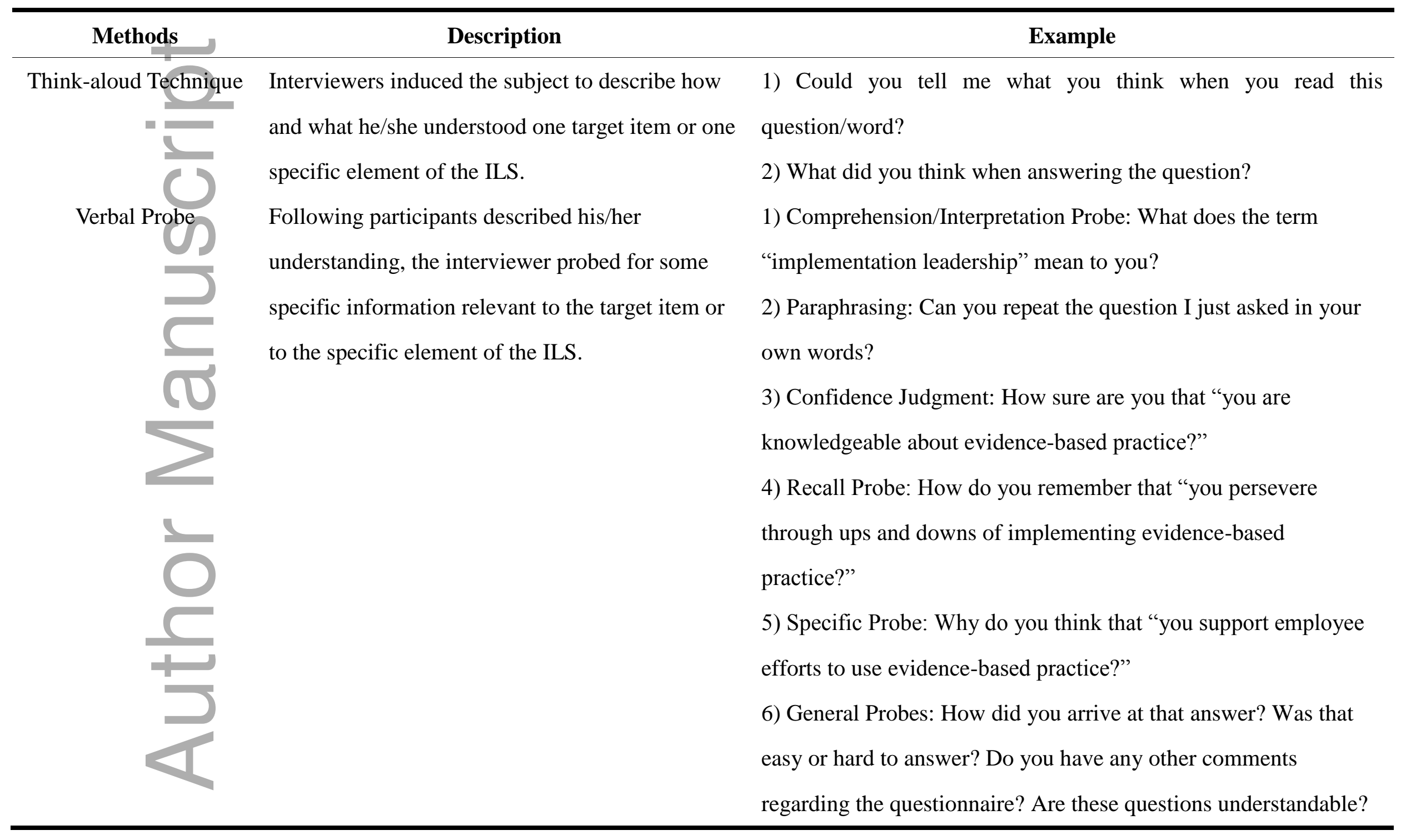

This article is protected by copyright. All rights reserved 


\section{Do you have any better suggestions on the format?}

$\begin{array}{ll}\text { Vignettes } & \begin{array}{l}\text { Vignettes are short stories or descriptions of a } \\ \text { hypothetical respondent that are used to }\end{array} \\ \begin{array}{ll}\text { investigate the participant's cognitive processing } & \text { 2) Do you think it is a good example of implementation on } \\ \text { with respect to survey-relevant decisions } & \text { evidence-based practice? }\end{array}\end{array}$

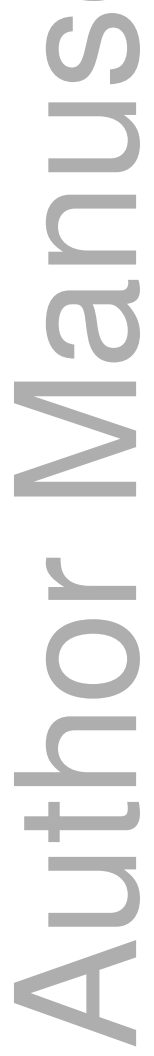

This article is protected by copyright. All rights reserved 
Table 3. Translation Issues in Forward and Backward Translation

\begin{tabular}{lcc}
\hline & Forward Translation, $\mathbf{n}(\boldsymbol{\%})$ & Backward Translation, n (\%) \\
\hline Number of Round & $\mathbf{2}($ Step $1-2,1-2)$ & $\mathbf{2}($ Step $1-4,1-4)$ \\
Rating Difficulty (22 items) & $3(13.64)$ & $1(4.55)$ \\
Two Translator & $7(31.81)$ & $3(13.64)$ \\
One Translator & $12(54.55)$ & $18(81.81)$ \\
No Translator & & $4(18.18)$ \\
Discrepancy (22 items) & $10(45.46)$ & $1(4.55)$ \\
Strong & $9(40.91)$ & $17(77.27)$ \\
Slight & $3(13.63)$ & $\mathbf{5}$ \\
No & $\mathbf{1 9}$ & 0 \\
Category of translation issues & $5(26.32)$ & $1(20.00)$ \\
Conceptual Equivalence & 0 & $4(80.00)$ \\
Operational Equivalence & $12(63.16)$ & 0 \\
Semantic Equivalence & $2(10.53)$ & \\
Item Equivalence & & \\
\hline
\end{tabular}

Note:

Conceptual equivalence: The translation is conceptually understood in the Chinese nursing context; Semantic equivalence: the translation is correctly reflected the intended English meaning; Item equivalence: the translation is accepted by targeted respondents; Operational equivalence: the translation has wording, format, instruction and scaling that could be used in Chinese nursing context.

This article is protected by copyright. All rights reserved 
Table 3. Demographic Characteristics of the Participants in Linguistic Validation

\begin{tabular}{|c|c|c|}
\hline Characteristics & $1^{\text {st }}$ Round $(n=10)$ & $2^{\text {nd }}$ Round (n=10) \\
\hline \multicolumn{3}{|l|}{ Sex } \\
\hline Female & 10 & 8 \\
\hline Mal & 0 & 2 \\
\hline \multicolumn{3}{|l|}{ Education } \\
\hline Doctoral Degree & 0 & 1 \\
\hline Master Degree & 1 & 2 \\
\hline Bachelor Degree & 7 & 5 \\
\hline College Diploma & 2 & 2 \\
\hline \multicolumn{3}{|l|}{ Position } \\
\hline Senior Nurse Leader & 1 & 1 \\
\hline Clinical Manager & 1 & 1 \\
\hline Head Nurse & 2 & 3 \\
\hline Nurse Educator & 1 & 1 \\
\hline Care Facilitator & 1 & 2 \\
\hline Bedside Nurse & 4 & 2 \\
\hline \multicolumn{3}{|l|}{ Working Years } \\
\hline $4 \sim 10$ & 2 & 4 \\
\hline $11 \sim 20$ & 6 & 4 \\
\hline$>20$ & 2 & 2 \\
\hline
\end{tabular}

This article is protected by copyright. All rights reserved 
Table 5. Linguistic Issues in Cognitive Interview

\begin{tabular}{lcc}
\hline & First Round, N $(\boldsymbol{\%})$ & Second Round, N $(\boldsymbol{\%})$ \\
\hline Response rate of participants & $10 / 14(71.43)$ & $10 / 12(83.33)$ \\
Length range & 27 min- $61 \mathrm{~min}$ & $16 \mathrm{~min}-47 \mathrm{~min}$ \\
Words range & $4610-11318$ & $3177-7302$ \\
Category of linguistic issues & $\mathbf{2 5}$ & $\mathbf{8}$ \\
Comprehension & $14(56.00)$ & $7(87.50)$ \\
Recall & $5(20.00)$ & 0 \\
Inference & $2(8.00)$ & $1(12.50)$ \\
Mapping & $3(12.00)$ & 0 \\
Editing & $1(4.00)$ & 0 \\
\hline
\end{tabular}

Note:

Comprehension: This reflects the encoding process; Recall: This captures the retrieval process; Inference: This reflects the judgment process; Mapping, which reflects the response process; Editing, which reflects the process of respondents' editing their answers

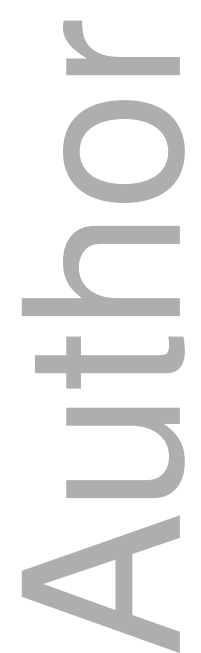

This article is protected by copyright. All rights reserved 
(7)

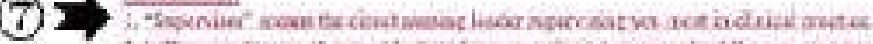

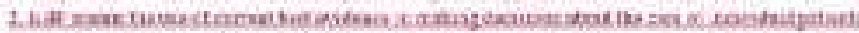

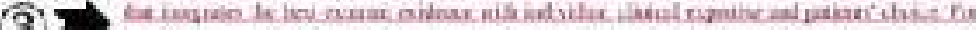

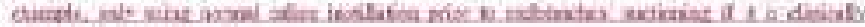

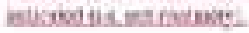

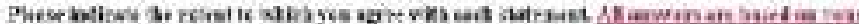

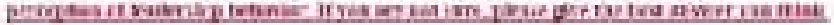

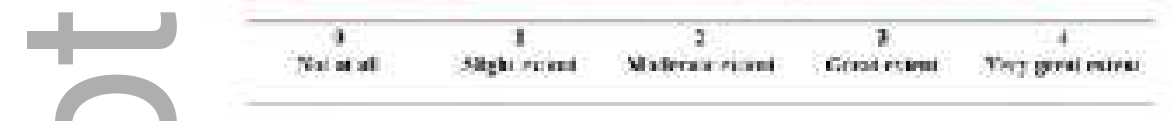

(B) 1 Poumb

$+$
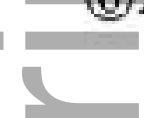

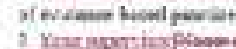

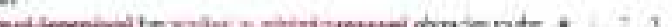

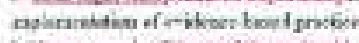

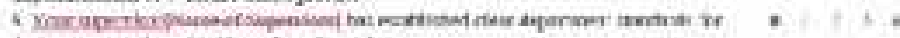

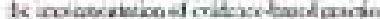

keeverpials

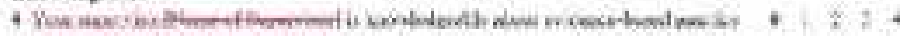

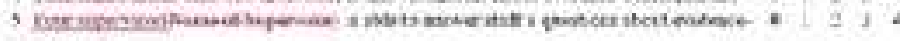

renc wave

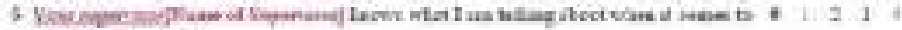

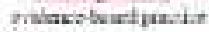

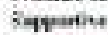

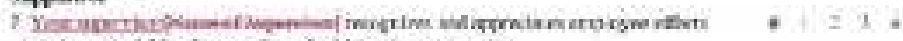

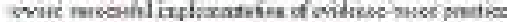

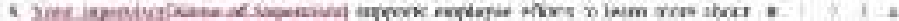

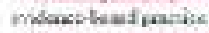

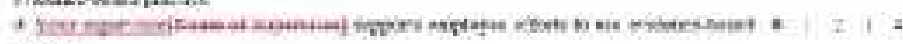
xestest

Menvertiant

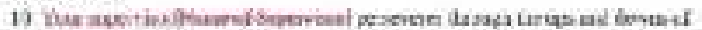

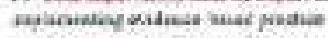

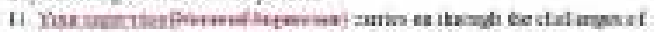

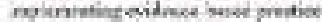

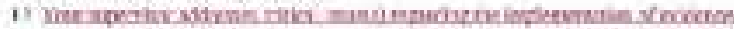

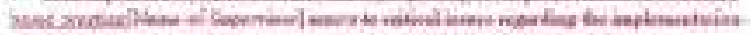

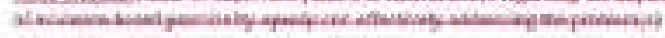

1 $1: \pm+$

- $1: 12+$

* $2 x=$

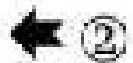

Stomanter takte

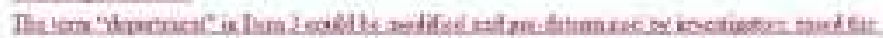

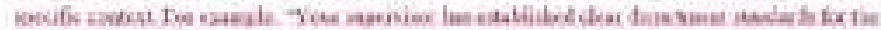

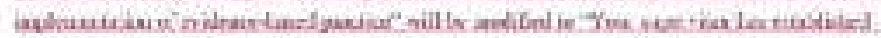

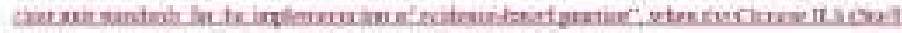

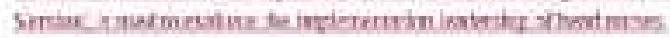

jonm_12768_f1.jpg 


\section{University Library}

\section{- M M N E R VA A gateway to Melbourne's research publications}

Minerva Access is the Institutional Repository of The University of Melbourne

Author/s:

Hu, J;Gifford, W;Ruan, H;Harrison, D;Li, Q;Ehrhart, MG;Aarons, GA

Title:

Translation and linguistic validation of the implementation leadership scale in Chinese nursing context

Date:

2019-07-01

Citation:

Hu, J., Gifford, W., Ruan, H., Harrison, D., Li, Q., Ehrhart, M. G. \& Aarons, G. A. (2019). Translation and linguistic validation of the implementation leadership scale in Chinese nursing context. JOURNAL OF NURSING MANAGEMENT, 27 (5), pp.1030-1038. https:// doi.org/10.1111/jonm.12768.

Persistent Link:

http://hdl.handle.net/11343/285765 